\title{
Role of ERK and JNK Pathways in Regulating Cell Motility and Matrix Metalloproteinase 9 Production in Growth Factor-Stimulated Human Epidermal Keratinocytes
}

\author{
MARY E. ZEIGLER, ${ }^{*}$ YIQING CHI, TANJA SCHMIDT, AND JAMES VARANI \\ Department of Pathology, The University of Michigan Medical School, \\ Ann Arbor, Michigan
}

\begin{abstract}
Invasion is an essential cellular response that plays an important role in a number of physiological and pathological processes. Matrix metalloproteinase (MMP) production and cell movement are diverse cellular responses integral to the process of invasion. The complexity of the invasive process suggests the necessity of coordinate activation of more than one signaling pathway in order to activate specific factors responsible for regulating these cellular responses. In this report, we demonstrate that cell movement and MMP-9 production are both directly dependent on the activation of endogenous ERK signaling in hepatocyte growth factor (HGF)-or epidermal growth factor (EGF)-stimulated human epidermal keratinocytes. The kinetic profiles of endogenous MEK and ERK activity suggest that prolonged activation of these signal transducers is an underlying mechanism involved in stimulating cell motility and MMP-9 production. In support of this finding, a transient MEK/ERK signal elicited by keratinocyte growth factor (KGF) or insulin-like growth factor-1 (IGF-1) fails to stimulate these invasion-related responses. Specific inhibition of MEK leads to suppression of ERK activation, marked reduction in steady-state levels of c-Fos, and inhibition of cell movement and MMP-9 production. This occurs despite continued activation of JNK and c-Jun signaling in the presence of MEK-specific inhibition. In contrast, when JNK activity is specifically inhibited in HGF-stimulated cells, AP-1 activity is suppressed but cell motility is not affected. This evidence suggests that while ERK and JNK activity are necessary for AP-1 activation, ERK but not JNK is sufficient in stimulating cell motility. J. Cell. Physiol. 180:271-284, 1999.

(C) 1999 Wiley-Liss, Inc.
\end{abstract}

Invasion plays an important role in a number of diverse physiological and pathological processes such as tissue remodeling associated with embryonic development (Symes et al., 1996), tissue regeneration and wound repair (Henke et al., 1996), angiogenesis (Camussi et al., 1997), and tumor metastasis (StetlerStevenson et al., 1993). In studies conducted in a number of experimental models, it appears that matrix metalloproteinase (MMP) production and cell movement are essential components of the invasion process (DeClerk et al., 1992; Liotta et al., 1979; Aznavoorian et al., 1996). In vivo, these invasive properties may be induced by a variety of stimuli including growth factors. Several growth factors including hepatocyte growth factor/scatter factor (HGF; Park et al., 1987; Komada and Kitmura, 1993; Bottaro et al., 1991; Weidner et al., 1993; Hartmann et al., 1992; Rong et al., 1992; Giordano et al., 1993), epidermal growth factor (EGF; McCawley et al., 1997; Price et al., 1996), insulin-like growth factor-1 (IGF-1; Jiang et al., 1996; Doerr and Jones, 1996), and keratinocyte growth factor (KGF; Marchese et al., 1990; Sato et al., 1995) have been shown to stimulate proliferative responses and to induce cell molility and/or the production of MMPs in vivo or in vitro in various cell types.

Because human epidermal squamous epithelial cells (keratinocytes) are known to be responsive to proliferative stimulation by these growth factors, we were able to assess the relative potency of these proliferative factors in inducing invasion of the dermis by epidermal keratinocytes. Using human skin explants (Fligiel and Varani, 1993; Varani et al., 1994, 1995) as an in situ model for studying mechanisms underlying growth fac-

Contract grant sponsor: USPHS; Contract grant number: CA 60958.

Tanja Schmidt is currently at the Department of Dermatology and Allergy, Biederstein Technical University Munich, Biedersteiner Strasse 29, 80802 Munich, Germany.

*Correspondence to: Mary E. Zeigler, Department of Pathology, University of Michigan, MS I, Box 0602, 1301 Catherine Road, Ann Arbor, MI 48109. E-mail: zeiglerm@umich.edu

Received 9 September 1998; Accepted 3 January 1999 
tor-dependent cell invasion, we determined that, in contrast to KGF or IGF-1 which did not stimulate invasion, HGF or EGF stimulated epidermal keratinocytes to invade the dermis (Zeigler et al., 1996a). This was inspite of the fact that all four growth factors induced a comparable proliferative response in these cells. We subsequently found that the invasion-promoting growth factors, HGF or EGF, unlike KGF or IGF, were potent stimulators of keratinocyte motility and MMP-9 production in these cells but not in dermal fibroblasts (Zeigler et al., 1996a,b). These finding suggested that cell motility and MMP production are invasion-promoting properties functionally linked to HGF- or EGF-stimulated epidermal keratinocyte invasion of the dermis.

The differences in the capacity of these growth factors to stimulate cellular properties associated with invasion suggested that comparative studies could be used to advantage as a basis for delineating the growth factor-dependent regulatory mechanisms that "drive" these responses. These differences may be due, in part, to differences in the kinetic properties of the signaling pathway(s) activated by HGF or EGF stimulation of their respective receptor protein tyrosine kinases (RTK) as compared to signals transmitted via these same pathways by KGF or IGF-activated RTKs. Recent evidence suggests that differences in the properties of the transmitted signal stimulated by nerve growth factor as compared to EGF in the same cell type may be a key factor in determining whether these cells proliferate or differentiate (Traverse et al., 1992, 1994).

The AP-1 transcription complex appears to play an essential role in stimulating transcriptional activation of several MMPs including MMP-9 (Sato and Seiki, 1993; Gum et al., 1996). In its active form, the AP-1 complex may comprise homodimers of c-Jun or heterodimers between c-Fos, c-Jun, and ATF2 (Karin et al., 1997; Smeal et al., 1989; Whisler et al., 1997). c-Jun proteins are activated by N-terminal phosphorylation of specific serine residues (Ser63/73) that appear to be exclusively activated by jun- $N$-terminal $k$ inases (JNKs), also known as stress-activated protein kinases (SAPKs). It has, therefore, been suggested that the JNK pathway is necessary in mediating MMP-9 production (Gum et al., 1997). However, c-Fos activation is not as strictly regulated. In this regard, the transcription factor, Elk-1, when phosphorylated induces c-Fos transcription which can be mediated either by activation of JNK or extracellular-regulated protein kinase (ERK) depending on cell type and cellular stimuli (Cavigelli et al., 1995).

It is likely that the ERK and JNK pathways are activated and work in concert to stimulate properties functionally linked to the growth factor-dependent invasive response in human epidermal keratinocytes. However, the exact mechanisms underlying the signaling properties of the endogenous ERK and JNK pathways that mediate the activation of these invasionpromoting cellular responses are not clearly defined; nor is it clear as to whether each of these pathways is necessary for stimulating both MMP-9 production and cell motility.

In this report, we examined in low-passage normal human keratinocytes, MAPK signaling in response to treatment either with HGF, EGF, KGF, or IGF-1. Con- comitantly, we examined the effects of interfering with signaling through the MAPK pathways on motility and MMP-9 production.

\section{EXPERIMENTAL PROCEDURES Reagents}

Commercial sources of reagents are as follows: keratinocyte growth medium (KGM), consisting of a keratinocyte basal medium (KBM) supplemented with EGF, insulin, hydrocortisone, and bovine pituitary extract, from Clonetics Corp. (San Diego, CA); HGF, EGF, KGF, and IGF-1 from R\&D Systems (Minneapolis, MN); sodium vanadate and 104 phosphate substrate from Sigma (St. Louis, MO); aprotinin, leupeptin, and pepstatin from Boeringher Mannheim (Indianapolis, IN); OPTITRAN (BA-S 85) nitrocellulose transfer membranes from Schleicher and Schuell (Keene, ME); MEK1-and MEK2-specific antibodies from Transduction Laboratories (Lexington, KY); phospho-specific ERK1/2 antibody (detects ERK1 and ERK2 only when activated by phosphorylation at Tyr204), phospho-specific SAPK/JNK antibody (detects three isoforms of SAPK/JNK only when activated by phosphorylation at Thr183/Tyr185), phospho-specific Elk-1 antibody (detects Elk-1 only when activated by phosphorylation at Ser383) and phospho-specific c-Jun antibody (detects only activated c-Jun when phosphorylated at Ser63), recombinant ERK2 fusion protein previously phosphorylated at Tyr204 after treatment with MEK1/2 in vitro and purified free of nonphosphorylated ERK1/2, GST-ELK-1 fusion protein (containing Elk-1 codons 307-428, encompassing the activating Ser383 amino acid critical to its transcription activity) and GST-c-Jun fusion protein (containing c-Jun codons 1-89, encompassing the activating Ser63/73 amino acids), Phototope-HRP Western detection kit containing LumiGlo reagent, and MEK inhibitor (PD098059) from New England Biolabs (Beverly MA); GST-ERK2 fusion protein (mouse p42 MAP Kinase-GST, expressed in Escherichia coli, serves as substrate for MEK kinase activity and exhibits kinase activity toward Elk-1) and GST-JNK fusion protein (rat SAP Kinase $\alpha$-GST agarose conjugate, serves as a substrate for SEK kinase activity and exhibits SEK-dependent kinase activity toward c-Jun) from Upstate Biotechnology Inc. (Lake Placid, NY); protein A-conjugated Sepharose CL-4B from Pharmacia (Uppsala, Sweden); SEK (MKK4)-specific antibody, antibody to JNK1(also crossreacts with JNK2), and ERK1 and ERK2 antibodies from Santa Cruz Biotechnology, Inc. (Santa Cruz, CA); FLAG antibody from Research Diagnostics Inc. (Flanders, NJ).

\section{Cell cultures}

Early passage cultures of human epidermal keratinocytes were isolated either from keratome strips obtained from adult volunteers or from neonatal foreskins according to the procedure of Boyce and Ham (1983). Primary or early passage cultures of human keratinocytes were grown in KGM. Cells were cultured at $37^{\circ} \mathrm{C}$ at a constant level of $5 \% \quad \mathrm{CO}_{2} / 95 \%$ air in a humidified incubator. Keratinocytes were routinely passaged after reaching $60 \%$ to $70 \%$ confluency and were typically used at passage 2 to 4 . When measuring the time-dependent phosphorylation or kinase activity of MEK, ERK, SEK, JNK, and c-Jun, early passage 
keratinocytes were first plated at $1.5 \times 10^{5}$ cells per $60-\mathrm{mm}$ culture dish. After $36 \mathrm{~h}$ of growth in KGM, the medium was withdrawn, cells were rinsed in KBM, and cultured in KBM for 6-7 h. The keratinocytes were subsequently cultured in the presence or absence of 3.5 nM HGF, 1.6 nM EGF, 6.7 nM IGF-1, or 15.8 nM KGF; these doses of reagents were previously determined to be optimal in stimulating epidermal invasion of the dermis in organ culture and in stimulating proliferation, MMP production, and motility of keratinocytes in culture (Zeigler et al., 1996a,b). Cells were subsequently harvested as described below.

\section{Preparation of cell lysates}

Following treatment of keratinocyte cultures with growth factors, cell lysates were prepared at the times indicated in the figure legends. Cells were lysed in $1 \times$ buffer consisting of $20 \mathrm{mM}$ Tris-HCl (pH 7.4), $2 \mathrm{mM}$ sodium vanadate, $1.0 \mathrm{mM}$ sodium fluoride, $100 \mathrm{mM}$ $\mathrm{NaCl}, 2.0 \mathrm{mM} \mathrm{10}$ phosphate substrate, $1 \% \mathrm{NP} 40,0.5 \%$ sodium deoxycholate, $25.0 \mu \mathrm{g} / \mathrm{ml}$ each aprotinin and leupeptin, $25.0 \mu \mathrm{g} / \mathrm{ml}$ pepstatin, $2.0 \mathrm{mM}$ each EDTA and EGTA. Lysis was performed at $4^{\circ} \mathrm{C}$ by scraping cells and then fragmenting cellular debris by several passes through a 26-gauge needle. Cell lysates were cleared by microcentrifugation at $12,000 \times \mathrm{g}$ following incubation at $4^{\circ} \mathrm{C}$ for $25 \mathrm{~min}$. The supernatant was recovered and the protein concentration of the lysates measured using the BioRad protein assay reagent (BioRad, Hercules, CA).

\section{Detection of MEK, ERK, SEK, and JNK phosphorylation by Western blot}

Equivalent amounts of cell lysate protein $(100 \mu \mathrm{g})$ were resolved by sodium dodecyl sulfate-polyacrylamide gel electrophoresis (SDS-PAGE; 12\%). Proteins were transferred to nitrocellulose membranes by electroblotting using a BioRad mini transfer blotting apparatus. Membranes were subsequently blocked in $\mathrm{Ca}^{2+} / \mathrm{Mg}^{2+}$-free Tris-buffered saline (TBS), containing $5 \%$ Blotto. Membranes were then treated with phosphorylation state-specific ERK1/2 antibody at a 1:1,000 dilution in $0.5 \%$ Blotto, TBS, and $0.1 \%$ Tween for $1 \mathrm{~h}$. Following several rinses in TBS, $0.1 \%$ Tween, the membrane-bound phosphorylated ERK1/2 protein was reacted with horseradish peroxidase (HRP)-conjugated goat anti-rabbit antibody at a 1:2,000 dilution for $1 \mathrm{~h}$. Phosphorylated ERK protein was detected by chemiluminescence involving treatment of the membrane with LumiGlo reagent and capture of light emissions to Xray film. The kinetics of ERK phosphorylation was quantified and depicted in graphic format after densitometric analysis of scanned x-ray images using the SHARP JX-320 scanner and the NIH Image analysis software program. Three to four exposures of immunoblots at specific intervals were taken in order to ensure that the band intensities of exposures depicted in each figure were within the linear range of detection by densitometry scanning. Changes in the levels of phosphorylation of ERK were depicted as a fold increase relative to $\mathrm{T}_{0}$ phosphorylation levels as a function of time. Phosphorylated MEK, JNK, and c-Jun proteins were detected in the same way, using samples of the same lysates previously used for detection of ERK1/2 phosphorylation, and depicted in the same graphic for- mat as for ERK. The phospho-specific primary antibodies detected only the phosphorylated form of each protein and did not crossreact with any of the other phosphoproteins. The steady-state levels of MEK, ERK, SEK/MKK4, JNK, and c-Jun proteins were measured using phosphorylation state-independent antibodies specific to each of these proteins.

\section{ERK kinase activity assay and MEK kinase cascade assay}

To verify the kinetics of the kinase active state of ERK, $300 \mu \mathrm{g}$ of cell lysate protein was immunoprecipitated with phospho-specific ERK antibody at a 1:100 dilution in $1 \times$ lysis buffer at $4^{\circ} \mathrm{C}$ for $16 \mathrm{~h}$. The immune complex was recovered by treatment for $3 \mathrm{~h}$ at $4^{\circ} \mathrm{C}$ with protein A-conjugated Sepharose CL-4B, previously hydrated in phosphate-buffered saline (PBS). After several washes in $1 \times$ lysis buffer, the pellet was subsequently rinsed in $1 \times$ kinase buffer $(25 \mathrm{mM}$ Tris $[\mathrm{pH}$ 7.5], $5 \mathrm{mM} \beta$-glycerolphosphate, $2 \mathrm{mM}$ dithiothreitol [DTT], $0.1 \mathrm{mM}$ sodium vanadate, and $10 \mathrm{mM} \mathrm{MgCl}_{2}$ ), then resuspended in kinase buffer containing $1 \mu \mathrm{g}$ of GST-Elk-1 substrate and $100 \mu \mathrm{M}$ ATP. The reaction proceeded for $30 \mathrm{~min}$, was terminated by the addition of SDS loading buffer, boiled for $5 \mathrm{~min}$, and resolved by SDS-PAGE (12\%). Immunoblotting was performed as described above, except that phosphorylated GSTElk-1 was detected using phospho-specific Elk-1 antibody. The positive control consisted of in vitro phosphorylation of GST-Elk-1 by active recombinant ERK2 previously added to and immunoprecipitated from time zero lysate protein with phosphospecific ERK antibody. The kinetics of ERK phosphorylation is depicted in graphic format after scanning densitometry as described above.

To evaluate MEK kinase activity in samples of these same lysates, a kinase cascade assay was performed in which MEK was immunoprecipitated in $300 \mu \mathrm{g}$ of cell lysate using $0.5 \mu \mathrm{g} / \mathrm{ml}$ each of MEK1- and MEK2-specific antibody. The immune complex was recovered and the kinase reaction performed as described above, except that a MEK subtrate, GST-ERK2 (mouse p42 MAP Kinase-GST) was included in the reaction. After 30 min, nonphosphorylated GST-Elk-1 substrate was added to the reaction which then proceeded for $30 \mathrm{~min}$. After the reaction was terminated by addition of SDS loading buffer, the samples were subjected to SDSPAGE (12\%) and immunoblotted. Controls for this kinase cascade assay included reacting immunoprecipitated MEK with GST-Elk-1 only or reacting only GSTERK with GST-Elk-1 to test the level of GST-ERK autoactivation in the absence of endogenous activated MEK1/2.

\section{SEK and JNK kinase activity assay}

Cell lysates were prepared from early passage keratinocytes stimulated with HGF or KGF for $0,2,10,30$, and $60 \mathrm{~min}$. The kinetics of activation of endogenous SEK was assessed using a kinase cascade assay in which $3 \mu \mathrm{g}$ of GST-JNK substrate conjugated to agarose beads was reacted with $250 \mu \mathrm{g}$ of cell lysate protein in lysis buffer at $4^{\circ} \mathrm{C}$ for $3 \mathrm{~h}$. The substrate was recovered by centrifugation, washed extensively in lysate buffer, rinsed, and reacted in kinase buffer with GST-c-Jun substrate to test the extent of kinase acti- 
vation by endogenous SEK. The extent of phosphorylation of GST-c-Jun by SEK-activated GST-JNK substrate was assayed by immunoblot using phosphospecific c-Jun antibody. Controls included a) reaction of GST-JNK with GST-c-Jun in the absence of SEK containing lysate protein to test the levels of GST-JNK autoactivation and b) testing the levels of the phosphorylated GST-c-Jun in the absence of GST-JNK. The background level of SEK-independent phosphorylation of GST-c-Jun by GST-JNK (lane, GST-JNK + GST-cJun) was substracted in the scanning densitometry depicting the kinetics of SEK kinase activity.

To confirm that the activation of GST-JNK is dependent on kinase active endogenous SEK, SEK was immunoprecipitated with SEK-specific antibody from samples of the same lysate protein referred to immediately above. The SEK-specific immune complex was recovered by centrifugation, after the addition of protein A-conjugated Sepharose CL-4B. Samples of the reserved lysate protein solution, which were from samples treated with $\mathrm{HGF}$ at 0,2 , and $10 \mathrm{~min}$, were subsequently combined with $3 \mu \mathrm{g}$ GST-JNK agarose-conjugated substrate and reacted for $3 \mathrm{~h}$ at $4^{\circ} \mathrm{C}$ in lysis buffer. After recovery of the substrate by centrifugation, the GST-JNK substrate was washed extensively in kinase buffer, then resuspended in kinase buffer containing $100 \mu \mathrm{M}$ ATP and the GST-c-Jun substrate. The reaction proceeded for $30 \mathrm{~min}$ at $30^{\circ} \mathrm{C}$ after which time the reaction was terminated by the addition of SDS sample buffer, boiled, and immunoblotted using phospho-specific c-Jun antibody.

Verification of the kinetics of the kinase active state of endogenous JNK was accomplished using an immune complex kinase assay. $250 \mu \mathrm{g}$ of lysate protein and JNK1 antibody was combined at $4^{\circ} \mathrm{C}$ overnight. The immune complex was recovered by centrifugation after treatment with protein A-conjugated Sepharose CL-4B as described above. The complex was washed in lysis buffer, then in kinase buffer, and subsequently resuspended in kinase buffer containing $100 \mu \mathrm{M}$ ATP to which $1 \mu \mathrm{g}$ of GST-c-Jun substrate was added and reacted for $30 \mathrm{~min}$ at $30^{\circ} \mathrm{C}$. The reaction was then terminated and the extent of JNK-dependent phosphorylation of the GST-c-Jun substrate was assayed by immunoblot using phospho-specific c-Jun antibody reactive only to phosphorylated serine 63 in the c-Jun protein. The background levels of the JNK-independent phosphorylated fraction of GST-c-Jun were substracted in the scanning densitometry of the kinetics of kinase active JNK.

\section{Proteinase assays}

Conditioned medium was reserved upon termination of migration experiments at $24 \mathrm{~h}$. Migration assays were performed as previously reported by us, (Zeigler et al., 1996a). The conditioned medium was assayed for MMP activity by gelatin zymography as previously described by us (Zeigler et al., 1996b). Briefly, equivalent amounts of conditioned medium were resolved by SDSPAGE (8.0\%) containing $1 \mathrm{mg} / \mathrm{ml}$ gelatin as a substrate to detect the gelatinolytic activity characteristic of MMP9. After electrophoresis, SDS was removed by several washes in $1 \%$ Triton X-100 and then the wash was continued overnight so as to renature the enzyme and recover gelatinolytic activity. Gelatinolytic activity is observed as a clear zone of gelatin substrate degradation visible after staining the gel with Coomassie Blue and destaining. In parallel, Western blotting with MMP-9-specific antibody confirmed the presence of the $92-\mathrm{kD}$ gelatinase in these samples of conditioned medium (data not shown). The differences in the levels of MMP-9 under various conditions were estimated by densitometric scanning using the SHARP JX-320 scanner and the NIH Image analysis software program.

\section{MEK/ERK signaling in the presence of PD098059}

In some cultures of keratinocytes, the MEK-specific inhibitor, PD098059 (Pang et al., 1995), was added to the $60-\mathrm{mm}$ culture dishes in KBM at the indicated doses for $30 \mathrm{~min}$. A stock solution of the inhibitor was prepared in dimethylsulfoxide (DMSO). The medium was then withdrawn and KBM-containing growth factor and inhibitor were added to the cultures for a period of $30 \mathrm{~min}$, after which time cultures were harvested and lysates prepared and assessed for activity as described above.

\section{Transfection of early passage keratinocytes}

Keratinocytes were transiently transfected with a dominant interfering mutant JNK(APF) (Derijard et al., 1994) generously provided by Roger L. Davis (University of Massachusetts Medical School and HHMI, Worcester, MA). pcDNA3.1 and/or AP-1/Luc, an AP-1dependent luciferase reporter plasmid, was provided by Stratagene (La Jolla, CA). Transfection of keratinocytes was performed using FuGene6 transfection reagent as described (Boehringer Mannheim). The expression construct was prepared in pcDNA3.1 (Invitrogen, Carlsbad, CA) into which the full-length JNK1 cDNA sequence containing the FLAG epitopetag was inserted. JNK1 requires phosphorylation of $\operatorname{Thr}(183)$ and $\operatorname{Tyr}(185)$ for activation. The JNK(APF) expression plasmid contains mutations in the JNK1 activation site in which Ala is substituted for Thr(183) and Phe is substituted for $\operatorname{Tyr}(185)$. As a result of these substitutions, the mutant JNK1 is rendered kinase inactive and unable to activate c-Jun. The AP-1 cisreporter plasmid consists of the luciferase reporter gene driven by a consensus promoter sequence (TATA box) linked to seven tandem repeats of the AP-1 consensus enhancer sequence.

\section{Luciferase reporter assay}

Early passage keratinocytes (passage 1) were plated at $150 \times 10^{3}$ in $35-\mathrm{mm}$ culture dishes and incubated for $24 \mathrm{~h}$. Cells were then transfected at a ratio of $4 \mu \mathrm{l}$ FuGene6 reagent to $3 \mu \mathrm{g}$ of DNA (1.5 $\mu \mathrm{g}$ of pJNK(APF) or pcDNA3.1 and $1.5 \mu \mathrm{g}$ of pAP-1/Luciferase reporter plasmid) or with JNK(APF) alone at a ratio of 4:3 in modified KGM containing HGF. In the same experiment, cells were also transfected at the same ratio of 4 $\mu \mathrm{l} \mathrm{FuGene}$ reagent to $3 \mu \mathrm{g}$ of DNA as described above but substituting the $\mathrm{pSV} / \beta$-galactosidase reporter plasmid for the pAP-1/Luciferase reporter plasmid. After $24 \mathrm{~h}$, the transfected cells were harvested by scraping in Tris-phosphate buffer containing DTT, Triton X-100, DCTA (diaminocyclohexane tetraacetic acid), and glycerol. Luciferase activity in the lysate was measured as a function of light production by the enzyme in the 
presence of beetle luciferin as substrate (Promega, Madison, WI). Luminescence was quantitated using a luminometer. $\beta$-galactosidase activity in cell lysates was measured as a function of hydrolysis of the colorless substrate (OPNG) to a colored substrate by $\beta$-galactosidase (Promega). Color formation was monitored by spectrophotometry. A standard curve of absorbance as a function of milliunits of $\beta$-galactosidase standard was used to determine the milliunits of enzyme activity in the lysate samples. Luciferase activity was reported as relative light units (RLU) normalized to milliunits of $\beta$-galactosidase activity. The results (see Fig. 7A) are representative of four separate experiments.

\section{Direct assessment of the motility of JNK(APF) transfected cells}

Keratinocytes were transfected with JNK(APF) or mock transfected as described above. After $24 \mathrm{~h}$, the cells were harvested and plated at $50 \times 10^{3}$ onto the upper surface of an uncoated membrane in the upper chamber of 24-well chambers (Biocoat, Becton Dickinson, Bedford, MA). The lower chamber contained either $\mathrm{KBM}$ or $\mathrm{HGF}$ in $\mathrm{KBM}$. After $18 \mathrm{~h}$ at $37^{\circ} \mathrm{C}$, the upper chamber was scrubbed with cotton swabs to remove cells that did not migrate. Cells that migrated to the undersurface of the membrane were subsequently fixed in $4 \%$ paraformaldehyde and then permeabilized with $0.2 \%$ Triton X-100. The filters were then rinsed and cells transfected with JNK(APF) were stained with FLAG-specific antibody (1:100 dilution) using Vectastain elite reagent kit (Vector Laboratories, Burlingame, CA). Mock-transfected cells were stained with hematoxylin. The number of cells visualized in five different fields by light microscopy was counted and reported as the mean cell number per field.

\section{RESULTS \\ Differences in kinetic properties of the endogenous MEK and ERK signaling intermediates in keratinocytes stimulated with invasion-promoting vs noninvasion-promoting growth factors}

Time-course analyses of endogenous MEK1/2 and endogenous ERK1/2 activation were performed to determine if differences exist in the kinetic properties of the signals transmitted by these endogenous signaling proteins when early passage keratinocytes are stimulated with HGF or EGF as compared to KGF or IGF-1. To evaluate the kinetics of activation of signaling intermediates in both the ERK and JNK pathways, we used phospho-specific antibodies that recognize only the kinase active forms of these signaling intermediates. The representative results of one of three individual experiments of the kinetics of activation of the MEK/ERK signaling intermediates are shown accompanied by a graphic display of the growth factor-dependent fold increase in MEK and ERK activation (Fig. $1 \mathrm{~A}, \mathrm{~B}$, respectively). Since MEK is the upstream activator of ERK1/2 (Seger and Krebs, 1995), we first assessed the time-course of MEK activation upon stimulation by each of the four growth factors using phosphospecific MEK1/2 antibody. As compared to MEK1/2 phosphorylation at time 0 (before stimulation with growth factor), maximal levels of MEK1/2 activation are evident by 2 min in keratinocytes stimulated with all four growth factors. However, only HGF and EGF maintain a prolonged period of nearly peak activation of MEK1/2 during $60 \mathrm{~min}$. We also found that this maximum activity persisted for at least $4 \mathrm{~h}$ (data not shown). In contrast, there is a decline in MEK1/2 activation in KGF or IGF-1-stimulated keratinocytes to nearly background levels by 30 min after initial peak activation at $2 \mathrm{~min}$. It is also apparent that there is no change in the steady-state (SS) accumulation of endogenous MEK1/2 in keratinocytes treated with HGF (Fig. 1A, SS) as determined by immunoblot assays using phosphorylation state-independent MEK1/2-specific antibody. Similar results were also obtained with the other three growth factors (data not shown). These results indicate that growth factor-specific differences in the profile of endogenous MEK phosphorylation are not the result of changes in the steady-state accumulation of MEK protein.

The time-course of endogenous ERK1/2 activation in keratinocytes treated with each of the four growth factors was evaluated using phosphorylation state-specific ERK1/2 antibody. The kinetics of ERK1/2 activation in cells stimulated with HGF or EGF reveals that maximum activation is apparent by $10 \mathrm{~min}$, persists with little change through $60 \mathrm{~min}$, and occurs within $8 \mathrm{~min}$ after the initial peak activation of MEK1/2 (Fig. 1B). Maximum activity extends through $4 \mathrm{~h}$ of stimulation with either of these two growth factors (data not shown). In contrast, there is only transient stimulation of ERK1/2 activation in cells treated with KGF or IGF-1. While ERK1/2 has been well characterized as the effector of MEK1/2, these kinetic profiles of endogenous MEK1/2 and ERK1/2 activation reveal how closely linked in time ERK $1 / 2$ activation is with MEK1/2. Furthermore, these results suggest that the kinetics of activation are differentially regulated by different ligand/receptor protein tyrosine kinase interactions. As was the case with MEK1/2 phosphorylation, the steady-state accumulation of ERK1/2 in cells treated with these growth factors does not change (Fig. 1B, SS)

To independently verify the kinase active state of endogenous MEK1/2 in these cell lysates, a kinase cascade assay was performed. Cell lysate protein prepared from keratinocytes stimulated for 30 min with HGF was immunoprecipitated with MEK1 and MEK2-specific antibodies and the immune complex subsequently reacted with the GST-ERK substrate followed by the addition of GST-Elk-1. The GST-Elk-1 substrate is a recombinant form of the endogenous Elk-1 transcription factor which is, in vivo, a substrate of active ERK1/2. Phosphorylation of the GST-Elk-1 substrate is detected using phosphorylation state-specific Elk-1 antibody which is reactive with the Elk-1 protein only when phosphorylated at Ser383, its activating site (Fig. $2 \mathrm{~B})$. The results of this assay indicate that in the presence of immunoprecipitated MEK1/2 and GST-ERK, GST-Elk-1 is phosphorylated (Fig. 2A, lane 1), although there is a modest level of autoactivation of GST-ERK in the absence of MEK1/2 (lane 3). In the absence of GST-ERK, but in the presence of immunoprecipitated enodgenous MEK1/2, GST-Elk-1 is not phosphorylated (lane 2), indicating that GST-Elk-1 phosphorylation is dependent on the activation of GSTERK by kinase-active endogenous MEK1/2. 


\section{MEK}

A

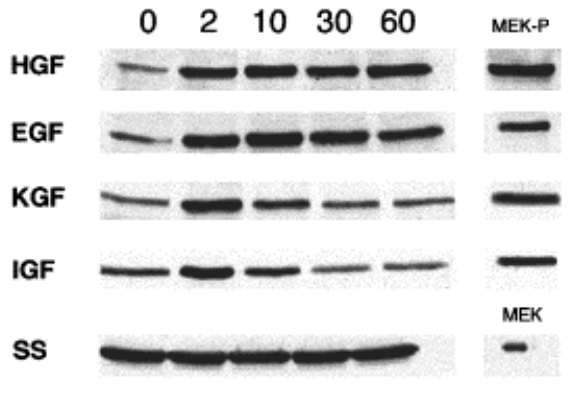

\section{ERK}

B

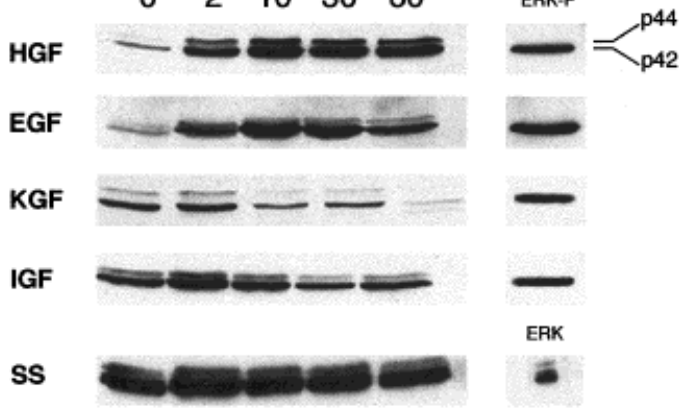

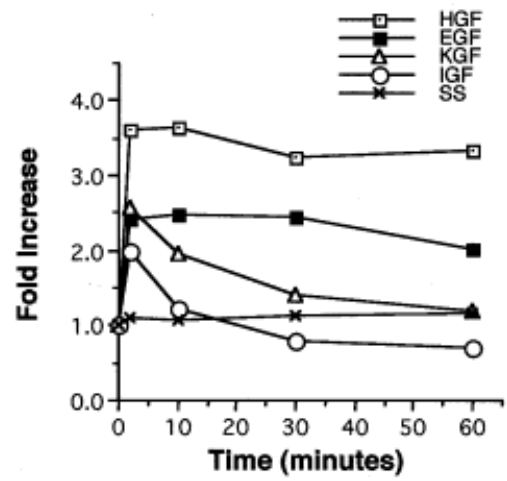

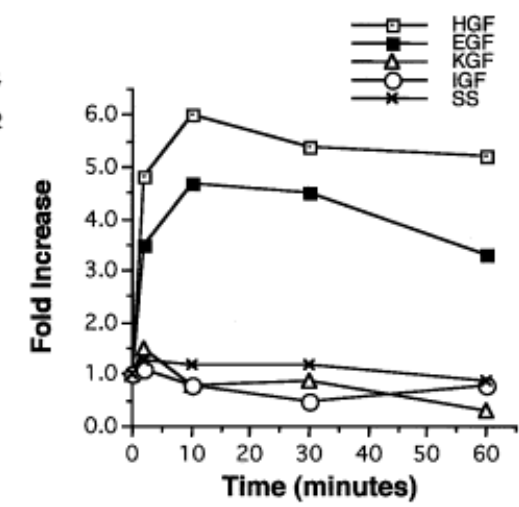

Fig. 1. Kinetics of growth factordependent activation of MEK1/2 and ERK1/2 kinase activity. Immunoblots of equivalent amounts of lysate protein $(100 \mu \mathrm{g})$ prepared from keratinocytes treated with either HGF, EGF, KGF, or IGF-1 and reacted with either phosphospecific MEK1/2 antibody (A) or phospho-specific ERK1/2 antibody (B). SS: The steady-state level of MEK1/2 protein (A) obtained by reaction with phosphorylation state-independent MEK1/2 antibody or the steady-state level of ERK1/2 protein detected by reaction with phosphorylation state-independent ERK1/2 antibody (B). Graphical representations of the kinetics of growth factor-dependent MEK and ERK activation and SS levels of these proteins are shown in panels A and B, respectively. Lane MEK-P: Positive control of activated MEK1/2 in lysate protein prepared from serum-stimulated NIH3T3. Lane ERK-P: Positive control consisting of recombinant ERK2 fusion protein ( $\mathrm{p} 42)$ phosphorylated and activated by treatment with $\mathrm{MEK} 1 / 2$ in vitro and purified free of nonphosphorylated ERK1/2.
An immune complex kinase assay was performed to test whether MEK1/2-dependent phosphorylation of ERK1/2 activated endogenous ERK1/2 kinase activity in HGF-stimulated keratinocytes in a time-dependent manner as compared to keratinocytes stimulated with KGF. An immune complex of endogenous ERK1/2 and phospho-specific ERK1/2 antibody was formed using cell lysate protein prepared from cells stimulated with HGF or KGF which were previously assessed for activation of endogenous ERK1/2 (Fig. 1B). The results indicate that endogenous ERK1/2 in HGF-stimulated keratinocytes is kinase active (Fig. 2B). A graphical representation of the kinetics of kinase-active ERK is depicted in Figure 2C. The data demonstrate a sustained level of ERK activity, which correlates with the kinetic profile of endogenous ERK1/2 activation (compare results in Fig. 2B with Fig. 1B). Similar results were obtained with EGF-stimulated keratinocytes (data not shown). However, the kinase activity of endogenous ERK1/2 in cells stimulated with KGF is transient and correlates with the kinetic profile of endogenous ERK1/2 activation by KGF (compare results in Fig. 2B with Fig. 1B).

\section{Kinetics of endogenous SEK and JNK kinase activity in growth factor-stimulated keratinocytes}

The invasive response stimulated by HGF or EGF results in an increase in MMP-9 production (Zeigler et al., 1996b). We found that an increase in MMP-9 production and activation is linked to epidermal kerati- nocyte invasion of the dermis and that MMP-9 is a secreted product of HGF- or EGF-stimulated keratinocytes (Zeigler et al., 1996a,b). The AP-1 transcription complex, which includes the c-Jun protein, is apparently essential for transcriptional activation of MMP-9 gene expression (Gum et al., 1997). Because activation of c-Jun is specifically dependent on the kinase activity of JNK (Derijard et al., 1994), which in turn is activated by SEK, the kinetics of activation of endogenous SEK and JNK were examined. The representative results of one of three individual experiments are shown accompanied by graphs depicting the growth factordependent fold increase in SEK and JNK activity (Fig. $3 \mathrm{~A}, \mathrm{~B})$.

The kinetics of activation of endogenous SEK was evaluated using a kinase cascade assay. This entailed reacting cell lysate protein, prepared from HGF- or KGF-stimulated keratinocytes, with a GST-JNK substrate conjugated to glutathione-agarose beads. This substrate exhibits serine-specific kinase activity toward c-Jun. The recovered GST-JNK substrate, if activated by endogenous SEK, will in turn react with the GST-c-Jun substrate phosphorylating the Ser63/73 codons. Phosphorylation of these two serine residues, in vivo, regulates the transcriptional activity of c-Jun. Using the phosphorylation state-specific c-Jun antibody, reactive only with activated c-Jun, we were able to measure the activation kinetics of SEK by assessing the kinetics of GST-c-Jun phosphorylation.

The results of this SEK-dependent kinase cascade assay demonstrate that endogenous SEK is activated 
A

\section{MEK Kinase Activity}

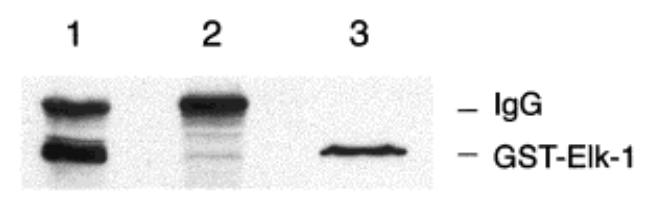

B

ERK Kinase Activity

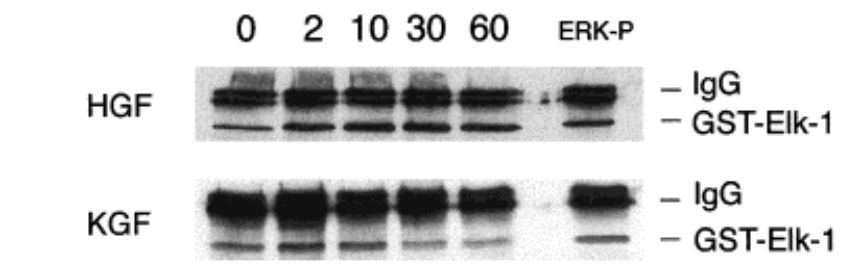

C

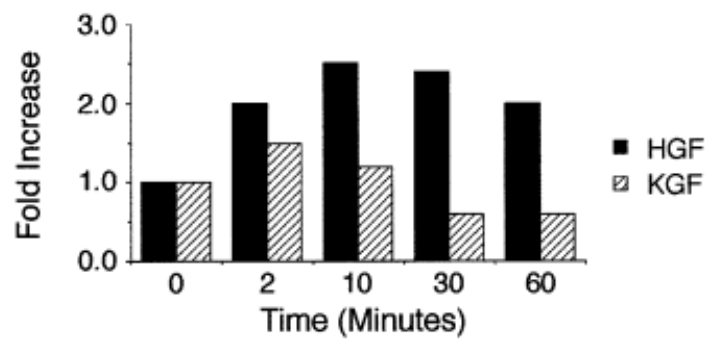

Fig. 2. Assessment of endogenous MEK and ERK kinase activity. A: Kinase cascade assay in which the endogenous MEK1/2 immune complex formed with MEK1/MEK2-specific antibodies using lysate protein prepared frorm HGF-stimulated keratinocytes was reacted either with the GST-ERK2 substrate (lane 1) or in the absence of this substrate (lane 2) and GST-Elk-1 substrate. GST-ERK was also reacted with GST-Elk-1 to assess the level of autoactivation of GSTERK in the absence of endogenous MEK1/2 (lane 3). Phosphorylation of GST-Elk-1 was detected by immunoblot using phospho-specific Elk-1 antibody. B: Immune complexes of endogenous ERK1/2 formed with phospho-specific ERK1/2 antibody from lysate protein prepared from HGF- or KGF-stimulated keratinocytes at the times indicated (in minutes) and then reacted with the kinase-inactive substrate, GST-Elk-1 protein. Phosphorylation of GST-Elk-1 was detected by immunoblot using phospho-specific Elk-1 antibody. ERK-P Control: Immunoblot of phosphorylation of GST-Elk-1 when reacted with kinase-active recombinant ERK. C: Graph of the immunoblot of ERKdependent phosphorylation of GST-Elk-1 in Figure 2B.

in keratinocytes stimulated with HGF and the kinetics of activation reveal a rapid increase to maximal activity by $10 \mathrm{~min}$ and then declines to near basal activity by $30 \mathrm{~min}$ (Fig. 3A, HGF). In contrast, there is virtually no activation of SEK in cells stimulated with KGF (Fig. 3A, KGF). However, the steady-state levels of SEK do not change in HGF-stimulated keratinocytes (Fig. 3A, $\mathrm{SS}$ ) or in KGF-stimulated keratinocytes (data not shown). This suggests that the differences in the profile of GST-c-Jun phosphorylation are the result of differences in the activation of endogenous SEK kinase activity.
We subsequently evaluated the time-course of endogenous JNK and c-Jun activation using the phosphorylation state-specific antibodies to each of these proteins. Endogenous JNK can be expressed as several isoforms including JNK1, comprising two isoforms, i.e., p46 and p54( $\gamma)$ or JNK2, p54( $\alpha)$. We used the phosphorylation state-specific JNK antibody, reactive only with the dually phosphorylated Thr183/Tyr185 kinase-activating amino acids expressed in all three JNK isoforms. Our results reveal that peak activation of $\mathrm{JNK}(\mathrm{p} 54$ ) occurs at $30 \mathrm{~min}$ and is transient in keratinocytes stimulated with HGF. JNK(p46) appears as a doublet in which peak activity occurs at $30 \mathrm{~min}$ and the signal appears stronger as compared to JNK(p54) (Fig. 3B, HGF). Unlike JNK(p54), JNK(p46) activation persists through $60 \mathrm{~min}$, despite the rapid decline in SEK activity. Coincidental with stimulation of endogenous JNK activation is an increase in the phosphorylation of endogenous c-Jun in HGF-stimulated keratinocytes, sharply increasing at $30 \mathrm{~min}$ and remaining above basal levels through $60 \mathrm{~min}$ (Fig. 3C, HGF). Similar results were observed in EGF-stimulated keratinocytes (data not shown).

In contrast to HGF stimulation, the kinetics of activation of endogenous JNK, in KGF-stimulated keratinocytes, is markedly different (Fig. 3B, KGF). There is virtually no increase in JNK activation above basal levels in keratinocytes not treated with growth factor $(0 \mathrm{~min})$. Instead, there is a progressive decline in phosphorylation of JNK below basal levels starting at 10 min and continuing through $60 \mathrm{~min}$. Consistent with these data, there is no change in the levels of phosphorylation of endogenous c-Jun in KGF-treated keratinocytes (Fig. 3C, KGF). There is also no change in the steady-state levels of the JNK and c-Jun proteins (Fig. $3 \mathrm{~B}, \mathrm{C}, \mathrm{SS})$, indicating that differences in the activation profiles are not the result of changes in the steady-state levels of these proteins.

We used a kinase cascade assay to evaluate the kinetics of endogenous SEK activation in lysate protein prepared from HGF-stimulated keratinocytes which depended upon SEK-specific activation of the exogenous substrate, GST-JNK (Fig. 3A, HGF). To further confirm that the kinase activation of GST-JNK is dependent on kinase-active endogenous SEK, we performed a SEK kinase activity control assay. In this experiment, endogenous SEK was immunoprecipitated with SEK-specific antibody from lysates prepared from keratinocytes stimulated with $\mathrm{HGF}$ at 0,2 , and $10 \mathrm{~min}$. After reaction of the SEK-depleted lysate protein with GST-JNK substrate, the kinase activity of this substrate was tested by reaction with GST-c-Jun substrate. As expected, there was no increase in levels of GST-c-Jun phosphorylation above background levels (Fig. 4A) as compared to levels of phosphorylation of GST-c-Jun in SEK-complete lysate protein at 0, 2, and $10 \mathrm{~min}$ in HGF-stimulated keratinocytes (Fig. 3A, HGF).

To directly demonstrate that endogenous JNK is kinase active and is capable of activating endogenous c-Jun, JNK was immunoprecipitated with JNK-specific antibody from samples of the same lysate protein used to assess the kinetics of JNK activation in HGF- or KGF-stimulated keratinocytes. JNK kinase activity was then evaluated by assessing changes in the level of 


\section{SEK}

A

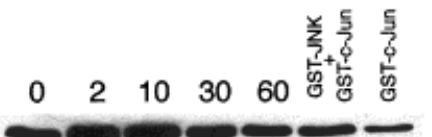

HGF

KGF

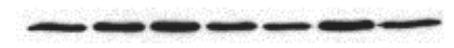

sS

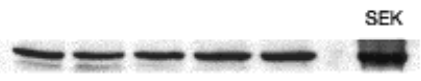

\section{JNK}

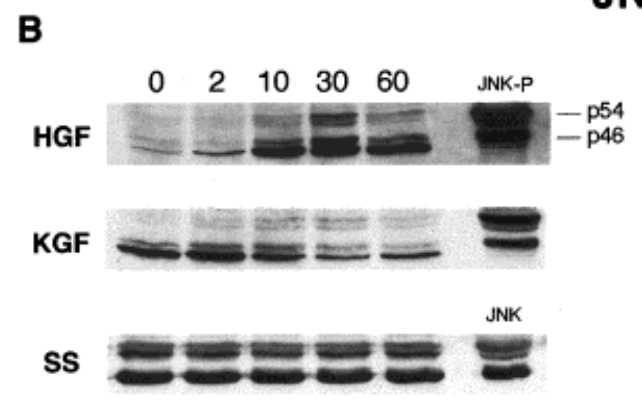

c-Jun

C

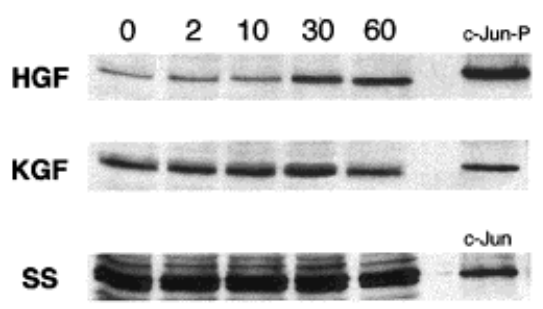

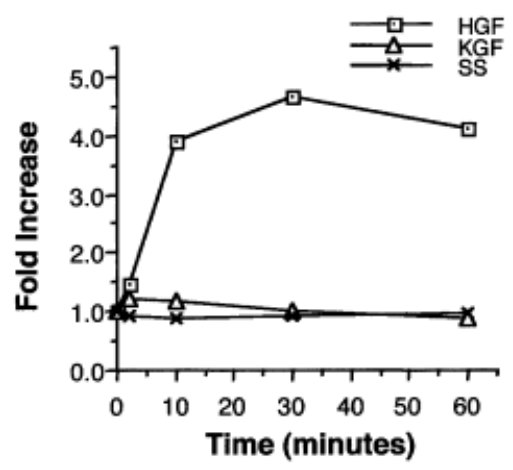

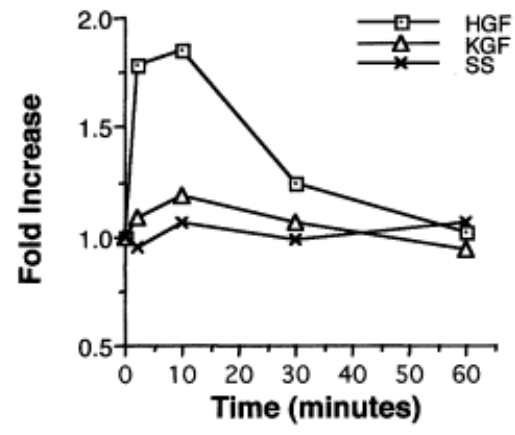

Fig. 3. Kinetics of growth factordependent activation of endogenous SEK, JNK, and c-Jun. A: Kinase cascade assay in which 250 $\mu \mathrm{g}$ of lysate protein from HGF- or KGF-stimulated keratinocytes for the indicated time intervals was combined with SEK-specific GSTJNK substrate conjugated to agarose beads. SEK-dependent activation of GST-JNK substrate was then assessed by GST-c-Jun phosphorylation levels in immunoblots using the phospho-specific c-Jun antibody. Lanes GST-JNK + GSTc-Jun: Combination of these fusion proteins in a kinase assay in the absence of lysate protein. Lane GST-c-Jun: SEK- and JNK-independent levels of phosphorylated GST-c-Jun. B, C: Immunoblots of equivalent amounts of lysate protein $(100 \mu \mathrm{g})$ prepared from keratinocytes treated with either HGF or KGF, then treated with either phospho-specific JNK antibody (B) or phospho-specific c-Jun antibody (C). Lane SS: The steady-state level of endogenous SEK, JNK, and c-Jun in equivalent amounts of lysate protein in HGF-stimulated keratinocytes assessed by reaction with phosphorylation stateindependent SEK, JNK, and c-Jun antibody. The kinetics of SEK, JNK, and c-Jun activation are displayed graphically in panels A, B and C, respectively. Lane JNK-P: Positive control of kinase-activated JNK in lysate protein prepared from UV-treated 293 cells. Lane c-Jun-P: Positive control of activated c-Jun in lysate protein prepared from UV-stimulated NIH 3T3 cells.
GST-c-Jun phosphorylation. As depicted in Figure 4B, the kinetic profile of GST-c-Jun phosphorylation in HGF- or KGF-treated keratinocytes corresponds to the kinetic profiles of endogenous JNK activation as previously shown (Fig. 3B). A graphical representation of the kinetics of the kinase-active JNK is shown in Figure $4 \mathrm{C}$.

Although these studies have focused primarily on the kinetics of two principal members of the MAPK family of signaling pathways, it should be noted that we also investigated whether the third principal member of the MAPK family (the p38 MAPK pathway) was similarly activated. We found that the activated form of p38 MAPK was detected by Western blot in cell extracts of C-6 glioma cells stimulated with anisomycin using phosphorylation state-specific p38 MAPK antibody. However, phosphorylated p38 MAPK was not detected in cell lysates of keratinocytes stimulated with either HGF or EGF (data not shown).

\section{Activated endogenous MEK regulates keratinocyte migration and MMP-9 production}

As we previously reported (Zeigler et al., 1996a), both $\mathrm{HGF}$ and EGF are potent stimulators of epidermal keratinocyte invasion of the dermis in a human skin explant model. Furthermore, there is direct correlation between induction of invasion and stimulation of keratinocyte motility and production of MMP-9 (Zeigler et al., 1996a,b). The data depicted above suggest that expression of these properties in HGF- or EGF-stimu- 
A

\section{SEK Kinase Activity Control}

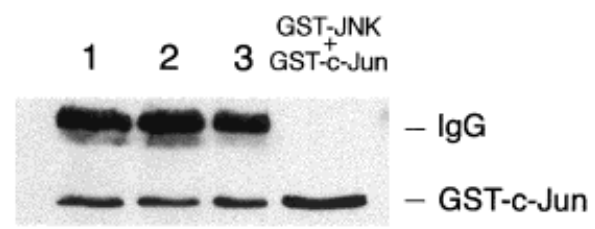

B

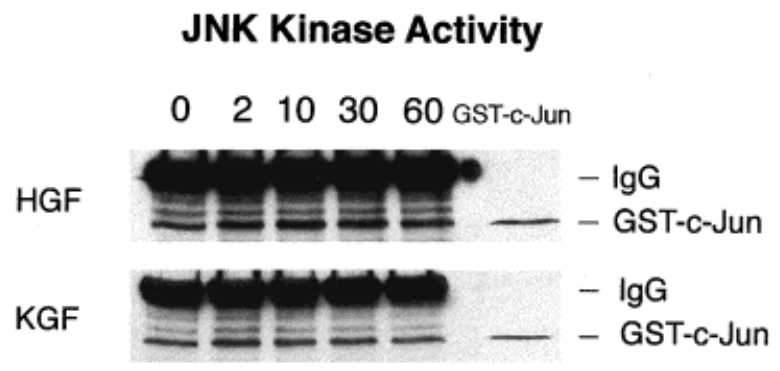

C

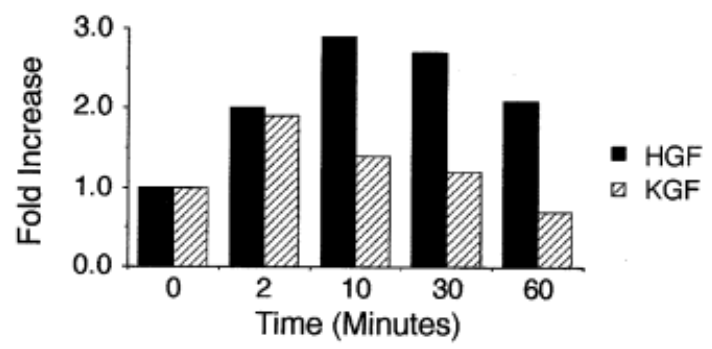

Fig. 4. Assessment of endogenous SEK and JNK kinase activity. A: Formation of immune complexes of equivalent amounts of lysate protein, prepared from keratinocytes stimulated with HGF for 0 min (lane 1), 2 min (lane 2), and 10 min (lane 3) as depicted in Figure 3, with SEK-specific antibody conjugated to agarose beads. The SEKdepleted lysate was recovered then GST-JNK substrate and GST-cJun substrate was added to this lysate as described in Experimental Procedures. Residual SEK activity was assessed by immunoblot blot using phospho-specific c-Jun antibody. Lane 4: GST-JNK+GST-cJun: GST-JNK combined with GST-c-Jun in the absence of SEKdepleted lysate. B: Immune complexes of endogenous JNK protein in lysates prepared from keratinocytes stimulated with either HGF or $\mathrm{KGF}$ at the times indicated (in minutes) with JNK1-specific antibody conjugated to agarose beads, then reacted with GST-c-Jun substrate and immunblotted with phospho-specific c-Jun antibody. Lane GSTc-Jun: SEK and JNK-independent phosphorylated GST-c-Jun. C: Graph of the immunoblot of JNK-dependent phosphorylation of GSTc-Jun in Figure 4B.

lated keratinocytes is associated with activation of the MEK/ERK and SEK/JNK signaling modules (Figs. 1, 3, respectively).

To determine whether the endogenous MEK/ERK signaling pathway is directly related to these biological activities, keratinocytes were treated with HGF and a MEK-specific inhibitor, PD098059 (Pang et al., 1995), which blocks MEK kinase activity. As shown in Figure $5 \mathrm{~A}$, endogenous ERK1/2 activation is inhibited in a dose-dependent manner in the presence of increasing amounts of MEK inhibitor. We also demonstrate that the effect of PD098059 on endogenous MEK1/2 is reversible such that kinase activity is regained and results in an increase in ERK1/2 phosphorylation after removal of the inhibitor but with continued treatment of keratinocytes with HGF (Fig. 5A, ERK). Furthermore, MEK1/2 activity also affects the steady-state levels of c-Fos such that in the presence of PD098059 there is a dose-dependent decrease in c-Fos protein levels that is also reversible upon removal of the inhibitor (Fig. 5A, c-Fos).

Having demonstrated the direct effect of PD098059 on MEK1/2 kinase activity, we also assessed whether keratinocyte motility is dependent on activated MEK1/2. In the absence of MEK inhibitor, there is more than a fivefold increase in the migration of keratinocytes treated with HGF as compared to cells treated with basal medium containing no growth factor (KBM) (Fig. 5B). However, with increasing concentrations of PD098059, there is a concentration-dependent decrease in migration.

The conditioned medium from the migration assay cultures was reserved and samples of this medium were assessed for changes in the levels of MMP-9 by gelatin zymography. Consistent with past results (Zeigler et al., 1996b), there is an increase in the amount of MMP-9 detected in the conditioned medium from HGF-stimulated keratinocytes compared to conditioned medium from cells treated with KBM (Fig. 4C). With increasing concentrations of MEK inhibitor, however, there is a concentration-dependent decrease in the accumulation of MMP-9. These findings demonstrate that the MEK/ERK signaling module is necessary for the production of MMP-9 and for the induction of cell migration of HGF-stimulated keratinocytes.

However, we found that there is no dose-dependent inhibitory effect of PD098059 on JNK or c-Jun phosphorylation compared to its effect on ERK1/2 phosphorylation (Fig. 6). These results show that neither JNK nor c-Jun are effectors of active MEK1/2 and, further, confirm that JNK and ERK activity are independent of each other. These results, however, raise the question as to the role(s) the JNK signaling pathway plays in stimulating the invasive response in HGF- or EGFstimulated keratinocytes.

\section{The JNK signaling pathway contributes to activation of the AP-1 complex but is not required for cell movement}

We know from previous studies that the AP-1 enhancer sequence in the promoter region of the MMP-9 gene is essential for the induction of MMP-9-specific mRNA leading to synthesis of MMP-9 protein (Gum et al., 1996). In light of our findings described above, it appears that the HGF-stimulated ERK pathway in early passage keratinocytes regulates c-Fos expression. We know that the transcriptionally active AP-1 complexes may comprise c-Fos:c-Jun heterodimers (Smeal et al., 1989). Since we clearly show that c-Jun activation remains unchanged when MEK1/2 activity is blocked and that activating phosphorylation of c-Jun is JNK dependent, then the production of the enodgenous AP-1 complex and its activation is also dependent on 
A

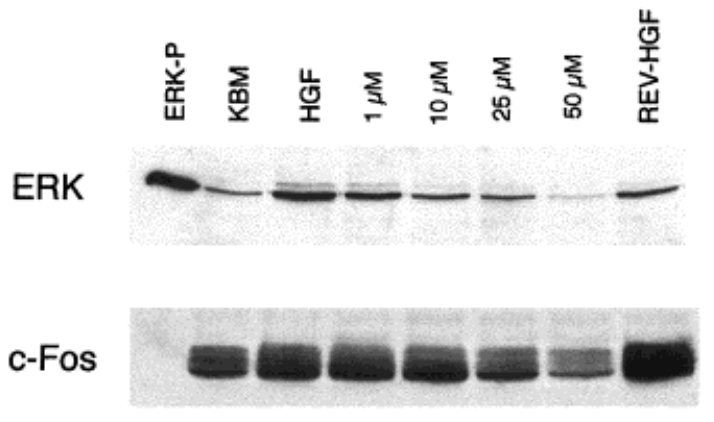

B

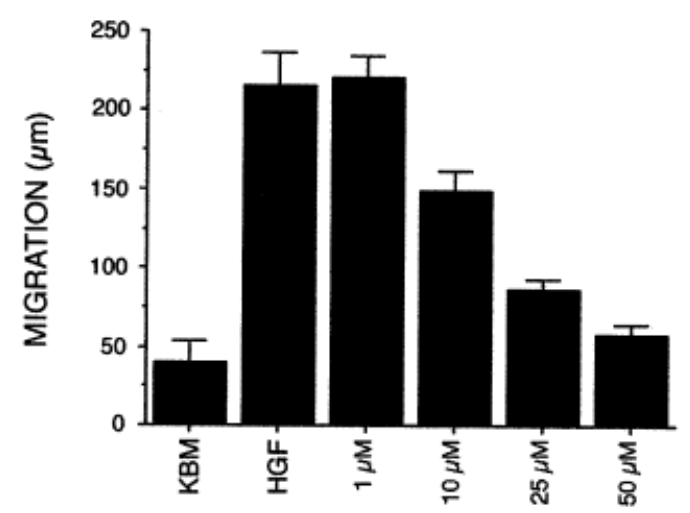

C

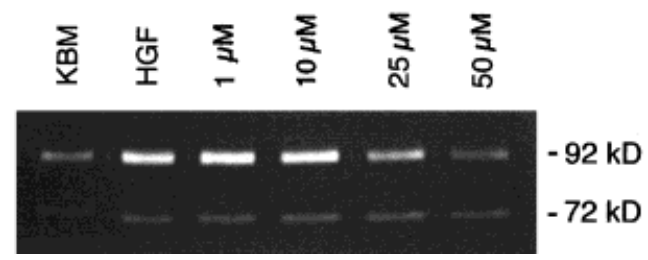

Fig. 5. The effect of MEK inhibitor(PD098059) on ERK kinase activity, cell movement, and MMP-9 production. A: Immunoblots of samples of lysate protein from keratinocytes stimulated with HGF either in the absence or presence of PD098059 at the indicated doses and reacted with either phospho-specific ERK antibody or c-Fos-specific antibody. Lane REV-HGF: Reversal of PD098059 effect by removal of the inhibitor and continued treatment with HGF for 30 min. Lane ERK-P: ERK2-positive control as described in Figure 1. B: The migration of keratinocytes after stimulation for $24 \mathrm{~h}$ with HGF in the absence or presence of PD098059 at the indicated doses. C: Gelatin zymography of equivalent amounts of conditioned medium from migrating cells in the presence and absence of $\mathrm{HGF}$, with and without the addition of the inhibitor.

activation of c-Jun by JNK in HGF-stimulated keratinocytes.

To evaluate the role of the JNK signaling pathway in the activation of the AP-1 complex in HGF-stimulated keratinocytes, these cells were cotransfected with an interfering mutant form of JNK, designated JNK(APF), and a luciferase reporter gene, designated AP-1/Luc, driven by an AP-1 enhancer sequence. The effect of blocking endogenous JNK activity on the formation of an active AP-1 complex was evaluated by measuring luciferase
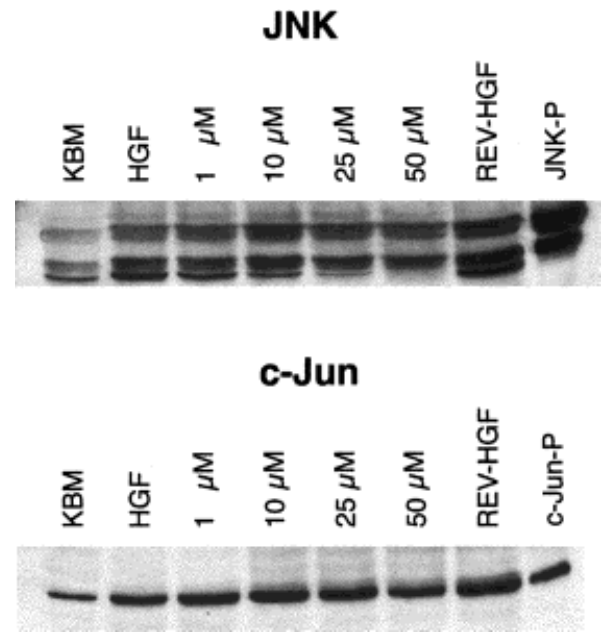

Fig. 6. The effect of MEK inhibitor on endogenous JNK and c-Jun activation. Immunoblots of samples of lysate protein, used to assess the effects of PD098059 on MEK and ERK activation in keratinocytes stimulated with HGF, treated with either phospho-specific JNK antibody or phospho-specific c-Jun antibody.

activity in these cells. We found that luciferase activity was blocked by $45 \%(P<0.001)$ as compared to cells cotransfected with the empty vector (pcDNA3.1) and AP1/Luc. These results suggest that formation of an active AP-1 complex is JNK dependent (Fig. 7A).

We then determined the effect of blocking JNK activity on HGF-stimulated keratinocyte motility. The assessment of changes in the migration of the JNK(APF)-transfected keratinocyte population can be directly measured and compared to the migratory capacity of nontransfected cells. To do this, we used chemotactic chambers in which JNK(APF)- or mock-transfected cells were stimulated by HGF. JNK(APF) cells which migrated to the underside of the porous membrane were immunostained with anti-FLAG antibody reactive to the FLAG-epitope tagged JNK(APF) protein, while motile, mock-transfected cells were stained with hematoxylin. We found that the JNK(APF)-transfected cells are motile and are, in fact, approximately twofold more active than mock-transfected cells (Fig. 7B). In the absence of HGF, no motile JNK(APF)-transfected cells are detected (data not shown).

\section{DISCUSSION}

Two essential properties of the invasive response are the capacity of cells to generate motile forces and the capacity to produce matrix-degrading proteinases which enables stimulated cells to penetrate extracellular matrix barriers. We undertook the studies presented here to examine the underlying mechanisms associated with the activation of endogenous intermediates in the MAPK signaling pathways which regulate these complex invasive properties.

While previous reports have presented evidence that sustained rather than transient activation of the MEK/ ERK signaling cascade leads to induction of cellular differentiation rather than proliferation (Traverse et al., 1992; Schramek et al., 1996), the studies we present here provide convincing evidence that pro- 
A

\section{AP-1/Luciferase Reporter Assay}

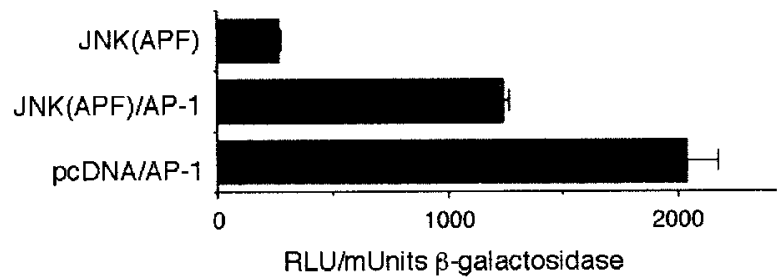

B

\section{Migration of JNK(APF) Cells}

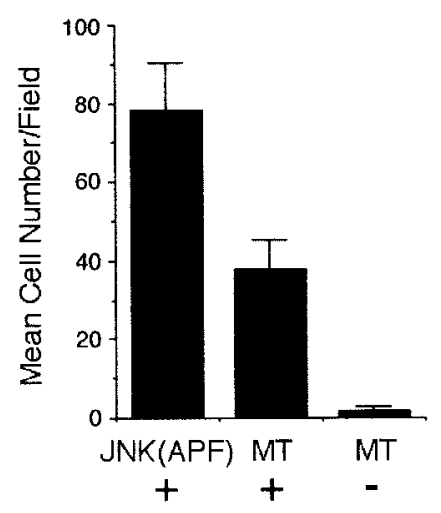

Fig. 7. The effects of dominant negative JNK(APF) on AP-1 activity and on cell migration in vivo. A: Early passage keratinocytes were cotransfected with either JNK(APF) and AP-1(Luc) or pcDNA3.1 and AP-1(Luc) or JNK(APF) alone. RLU of luciferase activity are normalized to $\beta$-galactosidase activity in the same cells transfected with a $\beta$-galactosidase reporter plasmid. B: Keratinocytes transfected with JNK(APF) or mock transfected (MT) were transferred to migration chambers and treated $(+)$ or not treated $(-)$ with HGF. Migrating transfected cells expressing the FLAG-tagged JNK(APF) protein in response to HGF stimulation were immunostained with FLAG-specific antibody and counted as described in Experimental Procedures. Mock-transfected cells that migrated in response to HGF were stained with hematoxylin and counted.

longed activation of endogenous MEK/ERK signaling is required in eliciting invasive responses in epidermal keratinocytes. Sustained activation initiated by HGF or EGF is an essential property of the MEK/ERK signaling pathway and is linked to a marked induction in cell movement and MMP-9 production. This is apparent when comparing the kinetics of activation of the MEK/ERK signaling module by each of the four growth factors (Fig. 1). Furthermore, the consequences of progressive interference of sustained activation of MEK is a dose-dependent decrease in ERK signaling and a progressive inhibition of both cell movement and MMP-9 production (Fig. 5). These results suggest that persistent activation of endogenous MEK and ERK is essential in stimulating cell movement and MMP-9 production. Because we previously found no marked differences in the proliferative responses of these cells to either the invasion-promoting or noninvasion-promoting growth factors (Zeigler et al., 1996a,b), it is likely that the mitogenic response in keratinocytes may be effectively stimulated by transient ERK signaling, while prolonged activation of the ERK pathway is required to stimulate invasive properties of cell movement and MMP production.

There are several mechanisms by which prolonged activation of ERK signaling may be achieved and thus regulate specific cellular responses. These include overexpression of cell surface receptors leading to an increase in the number of receptors at the cell surface (Traverse et al., 1994). Sustained signaling can also ensure translocation of activated ERK to the nucleus, thereby maintaining activating levels of transcription factor activity which stimulate specific cellular responses (Traverse et al., 1992). However, another important process in controlling protein kinase activation is regulated activation or deactivation of protein phosphatases. Both kinase-active MEK and ERK are likely targets that can be negatively regulated by protein phosphatase $2 \mathrm{~A}$ and protein tyrosine phosphatases and may thus modulate the properties of the ERK signaling pathway (Hunter, 1995). We think that sustained activation of ERK signaling in keratinocytes stimulated by $\mathrm{HGF}$ or EGF as compared to KGF or IGF-1 might reflect differences in the regulation of protein phosphatase activity by these growth factors. In keratinocytes treated with KGF or IGF-1, we consistently found a level of ERK activity that fell below the level of basal activity. This occurred as early as $10 \mathrm{~min}$ in cells stimulated with KGF or IGF-1 and suggests that transient ERK signaling by these growth factors may involve KGF- or IGF-1-dependent activation of phosphatase activity (Fig. 1B, KGF and IGF-1). In support of these observations, we have found that costimulation of keratinocytes with KGF and HGF converts HGF-induced ERK activation in keratinocytes to a transient signal and leads to a reduction in cell movement (unpublished data).

The AP-1 complex is essential in the production of several MMPs including MMP-9 (Sato and Seiki, 1993; Gum et al., 1996; Quinones et al., 1994; Gutman and Wasylyk, 1990). c-Jun activation, however, is ERK independent and, instead, is apparently activated exclusively by a distinct MAPK signaling module, SEK/JNK (Derijard, 1994). It, therefore, seems reasonable that in HGF- or EGF-stimulated keratinocytes, coordinate and prolonged activation of the endogenous JNK as well as ERK pathways is necessary to generate an increase in MMP-9 production. Our results show that like ERK, the activity of the p46 isoform of JNK1 (in contrast to the p54 isoform) is sustained. In conjunction with our findings that JNK activation is not affected by blocking MEK activity (Fig. 6), it is apparent that these pathways are activated independently but coordinately in keratinocytes stimulated by HGF, at least at the level of MEK and SEK activation (Figs. 2, 4).

Although persistent activation of MEK1/2 is evident in HGF-stimulated cells, by comparison SEK activation is transient in these cells (Fig. 3). While the kinetics of ERK activation further confirms its status as an effector of MEK1/2, the kinetics of JNK activation is 
sustained compared to the transient activation of SEK. These results raise the question as to whether SEK functions in vivo in HGF-stimulated keratinocytes as the principal activator of JNK. A recent report has shown that JNK activation occurs in homozygous "knock out" SEK (MKK4)(-/-) embryonic cells when these cells are exposed to osmotic shock or UV radiation, although the level of activation was reduced relative to levels in wild-type cells (Yang et al., 1997). However, in these same studies, it was also shown that JNK1 activity was suppressed when MKK4(-/-)cells were treated with anisomycin, heat shock, or when cotransfected with MEKK1 and JNK1. In a different set of studies, electrical stimulation of skeletal muscle contraction was found to result in a persistent kinetic profile of MKK4 activation which was mirrored in the kinetics of JNK activation (Aronson et al., 1997). Thus, the role that SEK(MKK4) plays in JNK activation may be conditional, i.e., depending on both the cell type and cellular stimuli. In HGF-stimulated keratinocytes, transiently activated SEK may share in the initial phase of JNK activation, while persistent activation of other SEK isoform(s), such as MKK7, may be necessary to prolong JNK activation (Tournier et al., 1997; Yao et al., 1997).

The invasive process is complex. As we have shown in these studies, it is mediated by the prolonged activation of at least two members of the MAPK signaling family. By interfering with the activation of either the ERK or the JNK pathway in HGF-stimulated keratinocytes, we have been able to characterize their specific roles in mediating the properties of the invasive response. The MEK-specific inhibitor studies reveal that blocking endogenous MEK1/2 activity suppresses HGF-stimulated ERK activity, reduces the steadystate levels of c-Fos, and inhibits MMP-9 production and cell migration (Fig. 5A-C). MEK inhibition, however, does not affect continued activation of JNK or its substrate c-Jun (Fig. 6). While specific and exclusive activation of c-Jun is mediated by JNK (Derijard et al., 1994), the activating domain(s) in c-Fos which regulates its transcriptional activity has not been precisely determined. There is evidence, however, that the Elk-1 transcription factor binds to the promoter region of c-Fos, thereby inducing c-Fos transcription and AP-1 activation (Cavigelli et al., 1995; Gille et al., 1995a,b; Chiu et al., 1988). Although JNK-dependent activation of the Elk-1 transcription factor can lead to induction of c-Fos expression by JNK, this usually occurs in UVstimulated cells. In cells stimulated by growth factors, Elk-1-mediated c-Fos expression is ERK dependent (Gille et al., 1995a). The evidence presented in Figures 5 and 6 clearly shows that in HGF-stimulated keratinocytes, c-Fos expression is ERK dependent and JNK independent. Coordinate activation of both pathways, then, appears to be necessary for the formation and activation of the AP-1 complex. Neither pathway is sufficient by itself to regulate MMP-9 production in HGF-stimulated keratinocytes.

We utilized a dominant interfering mutant of JNK [JNK(APF)] in order to characterize the role of endogenous JNK in mediating cell movement as well as in mediating endogenous AP-1 activity which has been shown to be essential for MMP-9 gene expression. Because in the cotransfection experiments, the probabil- ity is high that the majority of transfected cells harbor both plasmids, AP-1 activity only in the cotransfected population is measured as a function of luciferase activity. We were, therefore, able to demonstrate that JNK-dependent AP-1 activity is suppressed by nearly $45 \%(P<0.001)$ in JNK(APF)-transfected cells compared to cells transfected with the empty vector (Fig. 7A). It is possible, however, that these results underestimate the extent of suppression of AP-1 activity by JNK(APF) due to the presence of pre-existing active, endogenous AP-1 complexes. These background levels of active AP-1 may be due, in part, to the demands of maintaining the viability of early passage keratinocytes as well as levels of transfection efficiency. Because of these considerations, we were not able to remove growth factor supplements for a comparable length of time as was done in the kinetic studies in order to return signaling intermediates to basal levels of activity prior to stimulation.

These data, then, are consistent with JNK(APF) suppressing enodgenous JNK activity as measured by suppression of AP-1 activity. However, JNK(APF)-dependent inhibition of JNK activity did not suppress the motility of early passage keratinocytes stimulated by HGF (Fig. 7B). Unexpectedly, we found that JNK(APF)-transfected cells are more actively motile than mock-transfected cells. We speculate that suppression of JNK activity may indirectly relieve some restriction on the interaction of active ERK with downstream substrates involved in the generation of motile forces. In this regard, it was recently shown that myosin light chain kinase (MLCK), which is critical to the generation of contractile forces for cell migration, is a substrate of activated ERK (Klemke et al., 1997). These results suggest that activation of downstream targets of signals mediated by MEK/ERK signaling cascade may be all that is necessary to stimulate cell motility.

On the basis of the evidence presented here, it appears that the two MAPK pathways, ERK and JNK, are utilized differently in mediating the invasion-associated properties of cell motility and MMP-9 production in epidermal keratinocytes. The implications of these findings are that the JNK pathway is necessary for AP-1 activity which is essential for MMP-9 production but does not have a role in inducing cell motility in HGF- or EGF-stimulated keratinocytes. However, the ERK signaling pathway in HGF- or EGF-stimulated keratinocyte has a crucial role in the control of both properties of the invasive process. In this regard, strategies to block signaling via the MEK/ERK pathway could, in theory, disrupt both cell movement and breakdown of extracellular matrix barriers, thus controlling the invasive response in squamous epithelial cells. Furthermore, our kinetic studies, suggesting that signal duration is an essential property in mediating keratinocyte cell movement and MMP production, support the use of strategies for controlling the invasive process that do not require complete suppression of signaling. Instead, a method for converting MEK/ERK signaling to a transient phenotype may be sufficient in controlling the invasive response. A singular advantage of such a strategy is that transient signaling necessary for maintenance of other cellular responses is left intact. 


\section{LITERATURE CITED}

Aronson D, Dufresne SD, Goodyear LJ. 1997. Contractile activity stimulates the c-Jun $\mathrm{NH}_{2}$-terminal kinase pathway in rat skeletal muscle. J Biol Chem 272:25636-25640.

Aznavoorian S, Stracke ML, Parsons J, McClanahan J, Liotta LA. 1996. Integrin $\alpha_{\mathrm{v}} \beta_{3}$ mediates chemotactic and haptotatic motility in human melanoma cells through different signaling pathways. J Biol Chem 271:3247-3254.

Bottaro DP, Rubin JS, Faletto DL, Chan A, Kniecick TE, Vande Woude GP, Aaronson SA. 1991. Identification of the hepatocyte growth factor receptor as the c-met protooncogene. Science 251: 802-804

Boyce ST, Ham RG. 1983. Calcium regulated differentiation of normal human epidermal keratinocytes in chemically-defined clonal culture and in serum-free serial culture. J Invest Dermatol 81:33-40.

Camussi G, Montrucchio G, Lupia E, Soldi R, Comoglio PM, Bussolino F. 1997. Angiogenesis induced in vivo by hepatocyte growth factor is mediated by platelet-activating factor synthesis from macrophages. J Immunol 158:1302-1309.

Cavigelli M, Dolfi F, Claret FX, Karin M. 1995. Induction of c-fos expression through JNK-mediated TCF/Elk-1 phosphorylation. EMBO J 14:5957-5964.

Chiu R, Boyle WJ, Meek J, Smeal T, Hunter T, Karin M. 1988. The c-Fos protein interacts with c-Jun/AP-1 to stimulate transcription of AP-1 responsive genes. Cell 54:541-552.

DeClerck YA, Perez N, Shimada H, Boone TC, Langley KE, Taylor SM. 1992. Inhibition of invasion and metastasis in cells transfected with an inhibitor of metalloproteinases. Cancer Res 52:701-708.

Derijard B, Hibi M, Wu IH, Barrett T, Su B, Deng T, Karin M, Davis RJ. 1994. JNK1: a protein kinase stimulated by UV light and Ha-Ras that binds and phosphorylates the c-Jun activation domain. Cell 76:1025-1037.

Doerr ME, Jones JI. 1996. The roles of integrins and extracellular matrix proteins in the insulin-like growth factor 1-stimulated chemotaxis of human breast cancer cells. J Biol Chem 27:2443-2447.

Fligiel SEG, Varani J. 1993. In situ epithelial cell invasion in organ culture. Invasion Metastasis 13:225-233.

Gille H, Kortenjann M, Thomae O, Moomaw C, Slaughter C, Cobb MH, Shaw PE. 1995a. ERK phosphorylation potentiates Elk-1mediated ternary complex formation and transactivation. EMBO J 14:951-962.

Gille H, Strahl T, Shaw PE. 1995b. Activation of ternary complex factor Elk-1 by stress-activated protein kinases. Curr Biol 5:11911200 .

Giordano S, Zhen Z, Medico E, Goudino G, Galimi F, Comoglio PM. 1993. Transfer of motogenic and invasive response to scatter factor/ hepatocyte growth factor by transfection of human MET protoooncogene. Proc Natl Acad Sci USA 90:649-653.

Gum R, Lengyel E, Juarez J, Chen JH, Sato H, Seiki M, Boyd D. 1996. Stimulation of $92-\mathrm{kDa}$ gelatinase $\mathrm{B}$ promoter activity by ras is mitogen-activated protein kinase kinase 1-independent and requires multiple transcription factor binding sites including closely spaced PEA3/ets and AP-1 sequences. J Biol Chem 271:1067210680 .

Gum R, Wang H, Lengyel E, Juarez J, Boyd D. 1997. Regulation of 92 $\mathrm{kDa}$ type IV collagenase expression by the jun aminoterminal kinase- and the extracellular signal-regulated kinase-dependent signaling cascades. Oncogene 14:1481-1493.

Gutman A, Wasylyk B. 1990. The collagenase gene promoter contains a TPA and oncogene-responsive unit encompassing the PEA3 and AP-1 binding sites. EMBO J 9:2241-2246.

Hartmann G, Naldini L, Weidner KM, Sachs M, Vigna E, Comoglio PM, Birchmeier W. 1992. A functional domain in the heavy chain of scatter factor/hepatocyte growth factor binds the c-MET receptor and induces cell dissociation but not mitogenesis. Proc Natl Acad Sci USA 89:11574-11578.

Henke CA, Roongta U, Mickelson DJ, Knutson JR, McCarthy JB. 1996. CD44-related chondroitin sulfate proteoglycan, a cell surface receptor implicated with tumor cell invasion, mediates endothelial cell migration on fibrinogen and invasion into a fibrin matrix. J Clin Invest 97:2541-2552.

Hunter T. 1995. Protein kinases and phosphatases: the yin and yang of protein phosphorylation and signaling. Cell 80:225-236.

Jiang Y, Chan JL, Zong CS, Wang LH. 1996. Effect of tyrosine mutations on the kinase activity and transforming potential of an oncogenic human insulin-like growth receptor. J Biol Chem 271: $160-167$.

Karin M, Liu ZG, Zandi E. 1997. AP-1 function and regulation. Curr Opin Cell Biol 9:240-246.

Klemke RL, Cai S, Giannini AL, Gallagher PJ, de Lanerolle P,
Cheresh DA. 1997. Regulation of cell motility by mitogen-activated protein kinase. J Cell Biol 137:481-492.

Komada M, Kitamura N. 1993. The cell dissociation and motility triggered by scatter factor/hepatocyte growth factor are mediated through the cytoplasmic domain of the c-MET receptor. Oncogene 8:2381-2390.

Liotta LA, Abe S, Robey PG, Martin GR. 1979. Preferential digestion of basement membrane collagen by an enzyme derived from a metastatic murine tumor. Proc Natl Acad Sci USA 76:2268-2272.

Marchese C, Rubin J, Ron D, Faggioni A, Torrisi MR, Messina A, Frati L, Aaronson SA. 1990. Human keratinocyte growth factor activity on proliferation and differentiation of human keratinocytes: differentiation response distinguishes KGF from EGF family. J Cell Physiol 144:326-332.

McCawley LJ, O'Brien P, Hudson LG. 1997. Overexpression of the epidermal growth factor receptor contributes to enhanced ligandmediated motility in keratinocyte cell lines. Endocrinology 138: 121-127.

Pang L, Sawada T, Decker SJ, Salteil AR. 1995. Inhibition of MAP kinase kinase blocks the differentiation of PC-12 cells induced by nerve growth factor. J Biol Chem 270:13585-13588.

Park M, Dean M, Kaul K, Braun MJ, Gonda MA, Vande Woude G. 1987. Sequence of MET protooncogene cDNA has features characteristic of the tyrosine kinase family of growth-factor receptors. Proc Natl Acad Sci USA 84:6379-6383

Price JT, Wilson HM, Haites NE. 1996. Epidermal growth factor (EGF) increases the in vitro invasion, motility, and adhesion interactions of the primary renal carcinoma cell line A704. Eur J Cancer 32:1977-1982.

Quinones S, Buttice G, Kurkinen M. 1994. Promoter elements in the transcriptional activation of the human stromelysin-1 gene by the inflammatory cytokine, interleukin 1 . Biochem J 302:471-477.

Rong S, Bodescot M, Blair D, Dunn J, Nakamura T, Mizuno K, Park M, Chan A, AAronson S, Vande Woude G. 1992. Tumorigenicity of the met proto-oncogene and the gene for the hepatocyte growth factor. Mol Cell Biol 12:5152-5158.

Sato H. Seiki M. 1993. Regulatory mechanism of $92 \mathrm{kDa}$ type IV collagenase gene expression which is associated with invasiveness of tumor cells. Oncogene 8:395-405.

Sato C, Tsuboi R, Shi CM, Rubin JS, Ogawa H. 1995. Comparative study of hepatocyte growth factor/scatter factor and keratinocyte growth factor effects on human keratinocytes. J Invest Dermatol 104:958-963

Schramek H, Schumacher M, Pfaller W. 1996. Sustained ERK-2 activation in rat glomerular mesangial cells: differential regulation by protein phosphatases. Am J Physiol 271:F423-F432.

Seger R, Krebs EG. 1995. The MAPK signaling cascade. FASEB J 9:762-735.

Smeal T, Angel P, Meek J, Karin M. 1989. Different requirements for formation of Jun:Jun and Jun:Fos complexes. Genes Dev 3:20912100 .

Stetler-Stevenson WG, Aznavoorian S, Liotta LA. 1993. Tumor cell interactions with the extracellular matrix during invasion and metastasis. Annu Rev Cell Biol 9:541-573.

Symes K, Mercola M. 1996. Embryonic mesoderm cells spread in response to platelet-derived growth factor and signaling by phosphatidylinositol 3-kinase. Proc Natl Acad Sci USA 93:9641-9644.

Tournier C, Whitmarsh AJ, Cavanagh J, Barrett T, Davis RJ. 1997. Mitogen-activated protein kinase kinase 7 is an activator of the c-Jun $\mathrm{NH}_{2}$-terminal kinase. Proc Natl Acad Sci USA 94:7337-7342.

Traverse S, Gomez N, Paterson H, Marchall C, Cohen P. 1992. Sustained activation of the mitogen-activated protein (MAP) kinase cascade may be required for differentiation of PC12 cells. Comparison of the effects of nerve growth factor and epidermal growth factor. Biochem J 288:351-355.

Traverse S, Seedorf K, Marshall CJ, Cohen P, Ullrich A. 1994. EGF triggers neuronal differentiation of PC12 cells that overexpress the EGF receptor. Curr Biol 4:694-701.

Varani J, Perone P, Griffiths CEM, Voorhees JJ. 1994. All-trans retinoic acid and extracellular $\mathrm{Ca}^{2+}$ differentially influence extracellular matrix production by human skin in organ culture. Am J Pathol 142:1813-1822.

Varani J, Perone P, Inman DR, Burmeister W, Schollenberger SB, Fligiel SEG, Sitrin RS, Johnson KJ. 1995. Human skin in organ culture. Elaboration of proteolytic enzymes in the presence and absence of exogenous growth factors. Am J Pathol 146:210-217.

Weidner KM, Sachs M, Birchmeier W. 1993. The MET receptor tyrosine kinase transduces motility, proliferation, and morphogenic signals of scatter factor/hepatocyte growth factor in epithelial cells. J Cell Biol 121:145-154.

Whisler RL, Chen M, Beiqing L, Carle KW. 1997. Impaired induction 
of c-fos/c-jun genes and of transcriptional regulatory proteins binding distinct $\mathrm{c}$-fos/c-jun promoter elements in activated human $\mathrm{T}$ cells during aging. Cell Immunol 175:41-50.

Yang D, Tournier C, Wysk M, Lu HT, Xu K, Davis RJ, Flavell RA. 1997. Targeted disruption of the MKK4 gene causes embryonic death, inhibition of c-Jun $\mathrm{NH}_{2}$-terminal kinase activation, and defects in AP-1 transcriptional activity. Proc Natl Acad Sci USA 94:3004-3009

Yao Z, Diener K, Wang XS, Zukowski M, Matsumoto G, Zhou G, Mo R, Sasaki T, Nishina H, Hui CC, Tan TH, Woodgett JP, Penninger JM. 1997. Activation of stress-activated protein kinases/
c-Jun $\mathrm{N}$-terminal protein kinases (SAPKs/JNKs) by a novel mitogen-activated protein kinase kinase (MKK7). J Biol Chem 272: $32378-32383$

Zeigler ME, Krause S, Karmiol S, Varani J. 1996a. Growth factorinduced epidermal invasion of the dermis in human skin organ culture: dermal invasion correlated with epithelial cell motility. Invasion Metastasis 16:3-10.

Zeigler ME, Dutcheshen NT, Gibbs DF, Varani J. 1996b. Growth factor-induced epidermal invasion of the dermis in human skin organ culture: expression and role of matrix metalloproteinases. Invasion Metastasis 16:11-18. 